\title{
14
}

\section{GREENSPACE AS AN ELEMENT FOR A NEW URBAN DYNAMIC}

\author{
Fabienne Fendrich
}

Within the framework of the ArchéA Project in the Erasmus $+\mathrm{KA}^{2}$ Program, the approach is to focus on public space, with a particular question: how can greenspace become a constituent element in urban projects, creating a new urban and regional dynamic, beyond that of simply being a visual aspect of the project?

Analyzing the dynamics throughout France, over a long period of time, we can see that the country has been marked by three very different periods: until the end of the 18th century, France was predominantly rural; in the late 19th to early 20th centuries, France became urbanized and populations grew in medium-sized towns; today, the population of medium-sized cities is tending to decrease, while increasingly concentrating and developing in the metropolises. However, the pandemic we are currently experiencing has encouraged the exodus of the metropolitan populations toward large open spaces such as the countryside or the seaside, and greenspaces are seen as something of a new Eden. Our connection with spaces for nature, the way we perceive and use them, and how we consider our relationship to other living things are changing. It is clear that the current issues linked to the survival of man in his environment are obliging us to reinvent town planning projects and landscape design, reintroducing greenspaces into the city, as close as possible to its inhabitants. Reclaiming greenspaces, in order to live better in urban areas, has become an urgent matter.

Introducing nature back into the city is not just a testimony to the current situation. Greenspaces have always been present. This is linked to the survival of man. The first pastures and cultivated fields were developed as humans became sedentary. Along with large clearings, fences were introduced, in the form of hedges with thorny branches, in order to separate cultivated from non-cultivated areas. In the Middle Ages, life developed around the castle and inside the enclosure of the walls, and communities were pastoral. Nature was to be found inside the enclosure. This space looked empty but was in fact productive. Men lived alongside pigs, oxen, and poultry. Looking at the illuminations produced by le Maître de la Bible de Jean de Sy, as illustrations for the poetic works of Guillaume de Machaut, or the representations of spaces for nature in the Ruralium commodorum opus by Pierre de Crescent, one can easily see the close connections between humans and nonhumans, between 
what is considered as 'the city' and what is a space for 'nature'. Nature in the heart of the city is a means of subsistence. The city is not yet a place for show; rather, it is a place of contact between its inhabitants. Greenspaces were, in a way, one of the amenities that the city had to offer its inhabitants, urban resources that city dwellers had a right to expect.

The ideal of the Classical period was to consider the city as a theatre where one could witness the show of 'order'. Nature was moved away from the center, and the city's public square filled the space left. This was no longer a place for production but a place of prestige, the design of the facades in the square becoming a priority. A split between the city and the countryside took place. Nature began moving away from cities. Greenspace was returned to its place outside of the city and considered as a reserve of land available to meet the need for future expansion. Continuous pressure was exerted on this land due to its position in the urban landscape. It tended to be eaten into and to disappear. Greenspace no longer had a place in the city. The advent of the automobile and the shift from organic forms of energy to fossil fuels made the divide even more radical. However, the idea of nature was resisted as a kind of secular regression, and cities had parks and gardens almost as an artefact; thus, a certain concept of nature and natural spaces was developed. Parks were created in Paris out of a concern for health, as the inhabitants no longer had gardens. Nature in the city was nature brought in from elsewhere, closed in, artificial, and exotic. The parks were an expression of the demand for a certain quality of life. They were designed and planned to counteract urban development and densification, to meet the social demand for open, greenspaces. These spaces were above all for recreation and for access to an experience of nature and the social representation of such ideas. Parks and gardens were a little like the islands of an archipelago, lost in the middle of an ocean of buildings. The legacy of the Haussmann period in large cities was established according to a theoretical model, categorizing different spaces: public space was 'mineral' with aligned trees, gardens were protected, and isolated spaces, enclosed behind gates, and spaces for nature were to be found outside the city limits. The layout of urban spaces of the 19th century and at the beginning of the 20th century suggested nature as a framework, where gardens, parks, and forests would be interconnected (via walkways or greenbelts). From an educational and health point of view, trees became important: they renewed the air in the city and contributed to a healthy and pleasant environment. The presence of plants in urban spaces was seen as a decorative - albeit important - element. Greenspaces were considered as "islands" of nature.

In search of a more natural aesthetic for the layout of plants, a way of managing these spaces and how they functioned were then taken into consideration. Considering living things as a fundamental basis means imagining the process at different scales. Living organisms cannot be contained in simple geometric figures or in straight lines. It is more a question of fractal geometry than Euclidean geometry. In which case, our role is less about the preservation of a particular state and more about allowing certain processes to happen, creating a constructive interaction between greenspaces and urban spaces.

Gilles Clément was undoubtedly the precursor of this theory which aims to redefine the role of man in nature. Thanks to his observations and practical experiments in his own garden La Vallée in the French département of la Creuse, Gilles Clément applied the concept of the Jardin en Mouvement (the "Garden in Motion") to public spaces, an example being the Parc André Citroën inaugurated in 1999. For Gilles Clément, the "Garden in Motion" is a way of managing and, therefore, of designing a garden: plant species can grow and develop freely. This approach is about fostering cooperation with nature, giving observation 
an important role. The project develops through time and space. The protection of nature is dynamic and not static and is focused on finding the best possible adaptation to the site ("Do as much as possible 'with', and as little as possible 'against'”; Figure 14.1).

In a similar way, Le Champ Libre, formerly the Parc des Bruyères, located in Rouen, testifies to this approach, where the management of greenspaces generated new uses. The landscape design office Mutabilis has been working on the transformation of this former racecourse since 2018. Le Champ Libre (meaning 'open field' and also 'open, free space') includes two main parts: one on the avenue des Canadiens, and the other on the rue du Madrillet. This wideopen space includes a large grassy area of $25,000 \mathrm{~m}^{2}$, with small wooded areas or copses, which can be used for picnicking, playing games, or for large public events. To the east, the second area, now called the "edible forest," has more trees. A sustainable urban agriculture project is being developed, focusing on respect for the environment and including a preservation orchard and a "grazed forest" with sheep and horses. The Metropolis of Rouen Normandie also wanted to include a 2.5-hectare permaculture farm. As project leader, they are both owner and manager of the land. The Metropolis also invested in some of the farm facilities. Besides its economic function, the permaculture farm is also a showcase for how this approach is being developed locally elsewhere. Certified as an organic farm, the project organizes and develops outreach activities to raise awareness of urban agriculture, as well as offering training for farmers, in particular for permaculture and organic farming techniques.

This space given to nature should be considered as part of a new dynamic for urban planning. It is not only an ecological corridor that cuts into the heart of the city but also an extraordinary reservoir of biodiversity, an area giving protection to both humans and nonhumans. Here it is a question of reclaiming greenspace as an element giving structure to the city's development: a solution providing continuity and a complementarity of uses and social connections, between the different components of nature present in the urban fabric.

Another exemplary, experimental area is the Transformateur site located at Saint-Nicolasde-Redon in the Loire-Atlantique, along the valley of the Vilaine river. On the border of three neighboring French départements - Loire-Atlantique, Ille-et-Vilaine, and Morbihan the site is at the heart of an urban center with nearly 20,000 inhabitants. Historically, this

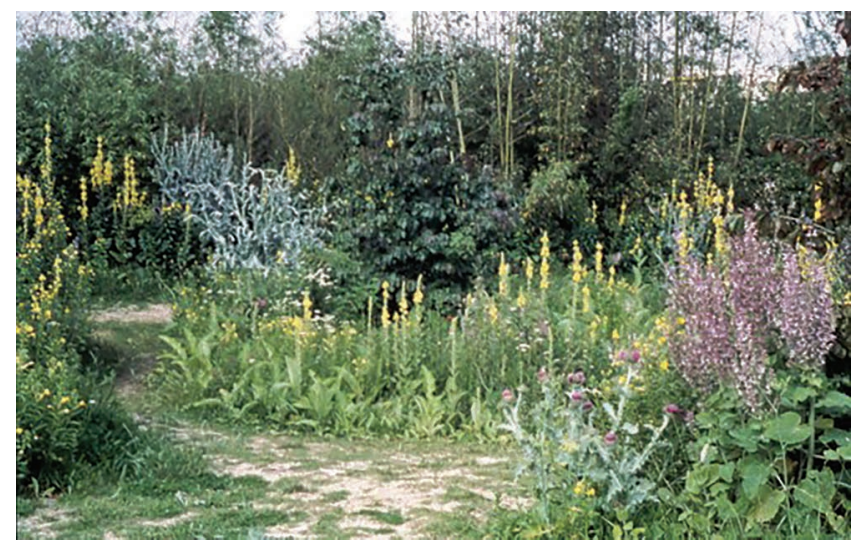

FIGURE 14.1 Jardin Javel Citroën. Concepteur Gilles Clément. Photo (C) Fabienne Fendrich, 2016. 
wetland had been used by industry (the Sébilleau factory, and the gradual extension of other industrial zones, the SEMES factory, then the LECOQ company, a supplier of agricultural equipment). In 2000, the site was abandoned due to repeated flooding. From 2005, the site was taken over by the Conseil Général of the Loire-Atlantique. The creation of practical educational workshops on site by the École Nationale du Paysage de Versailles (a national landscape school) has made it possible to gradually build a landscape of hope, based on cultural development. At the Transformateur site, the rule is simple: do it together, using everything there is available on site. The rule is also to not remove anything from the site or import anything and, therefore, to use only what is available on site, with a real economy of means. Anything can be a raw material: it is simply a matter of tidying up, organizing, and prioritizing activities on site. This is a reversal of the system. It is nature reconquering the site, acting as a magical driving force for the project and guiding its development. Non-recyclable waste can be stored and becomes a revitalized gabion wall, an old metal tank becomes a stork's nest, and a pile of old tree stumps becomes a rabbit warren, creating a "jard'andain" or "windrow garden." Places previously marked by time and industry are reconquered in a reasoned and original natural process, where urban developments can be gradually added (Figure 14.2).

Admittedly from the smaller scale of parks and gardens, these experiments can be developed on a larger scale, initiating a new paradigm for the creation of a city. The idea is to allow the city to integrate a natural flow or progression. The city should no longer try to stop constant exchange. The city must allow for mobility. What matters is no longer what the city encloses but rather its capacity to be influenced by that which moves through it. This is the case in Caen for the site La Prairie. La Prairie is a green landmark, of great historical and natural interest: covering 90 hectares and located in the city center, it is a place for recreation, jogging, or taking a stroll, but it also acts as a spillway in case of flooding. The city of Caen developed in a marshy valley, crossed by the Orne river and its tributaries, les Odons, as well as by a Roman road. Urbanization occurred between this Roman road and the Odon rivers. As early as 1027, La Prairie is mentioned in a text that qualifies it as "belonging to the Duke." Through a series of acquisitions and donations, a part of these

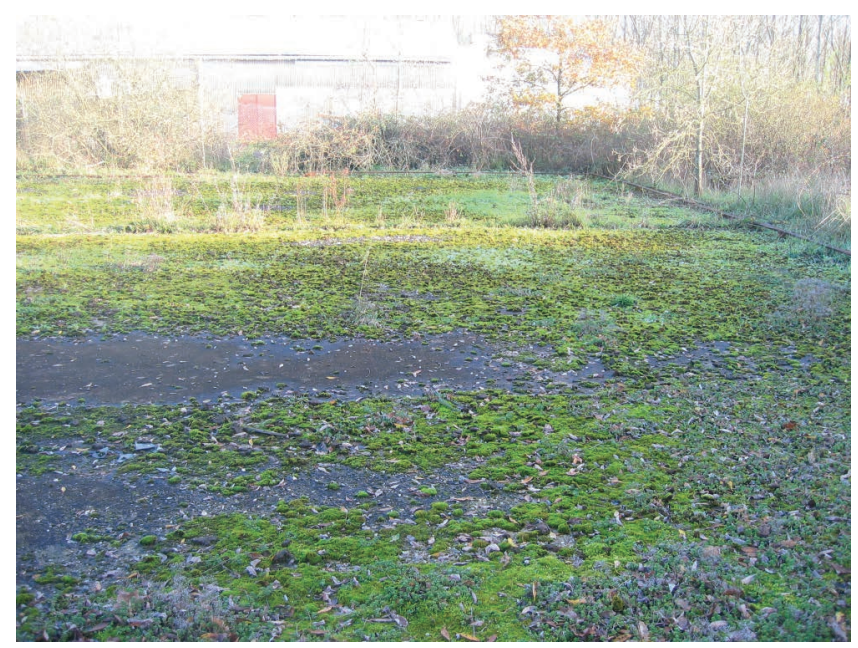

FIGURE 14.2 Transformateur de Redon. Photo CFabienne Fendrich, 2006. 
meadows, known as La Prairie de l'Abbé, came under the control of the Abbaye-aux-Hommes. This did not prevent the inhabitants from grazing their animals there during periods of regrowth of the grass. This tradition was passed on by Norman law up until contemporary times. In 1837, the first trotters' horse race was organized in La Prairie. The site was later listed in the inventory of 1932, as a protected area, liable to flooding. La Prairie is a natural wetland, a site for rural observation and a place for discovering the local flora and fauna. It plays an essential role in the flood management of the Orne. Special protection measures have been introduced, aimed at preserving its character and reinforcing its recreational uses. It is defined as a protected natural zone (zone $N d a$ in the French land-use plan) as it is particularly exposed to the risks of flooding from the Orne. Improvements include clearing work for botany and entomology studies, re-profiling the ditches to create gentle slopes, and reworking parts of the banks of the pond, to allow for better interactions (between plants, insects, amphibians, birds), without disturbing the natural state of these places. La Prairie is thus a place not only for the social life of the people of Caen but also for herons, cormorants, moorhens, and black-headed gulls or snipes, rarely found in such proximity to a city. There is thus the idea of a shared, dynamic ecosystem, which welcomes a choreography with several participants, human and nonhuman, revealing shared rhythms and fragile, ephemeral trajectories (Figure 14.3).

Greenspaces existed before urbanization. Being rooted in these spaces allows the city to continue to develop, placing it in a natural flowing process that goes beyond the initial design. The combined notions of urban development and protection of nature, which are a priori contradictory, can in fact help to reverse this paradox, creating a constructive interaction between natural spaces and the urban spaces where they are integrated, the latter contributing to the protection of urban nature. This was the case with the development of the beach in Le Havre, designed by Alexandre Chemetoff in 1994, and carried out together with the Landscape Office and with the technical services of the city of Le Havre. The idea was to enhance the seafront of the city, at the time much more focused on the estuary and its port activities. The development project reorganized the passage from the sea to that of the

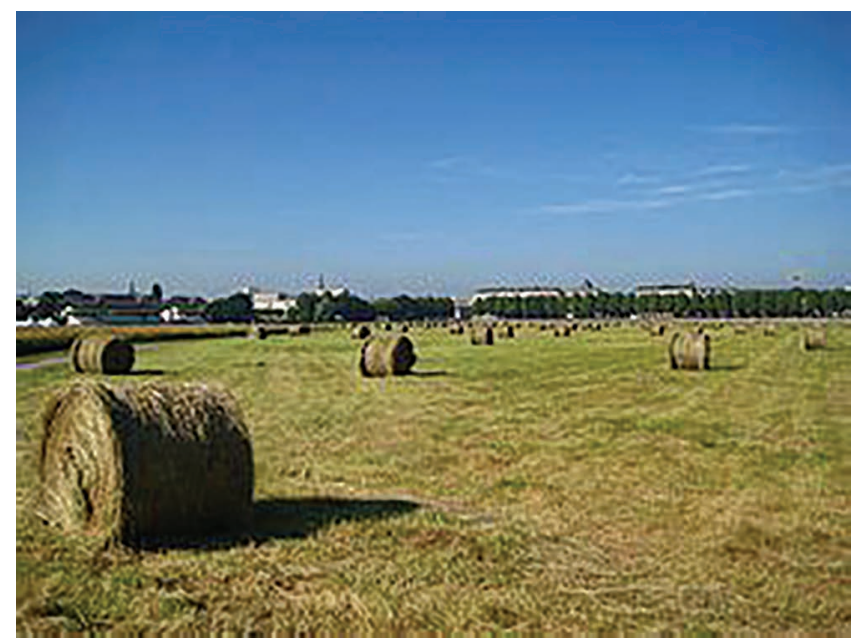

FIGURE 14.3 La Prairie de Caen. Photo libre de droits. 
city. The two elements - natural space and urban space - were no longer simply juxtaposed but instead intimately linked, through different transitional spaces. Different horizons, uses, and timescales all came into consideration. Alexandre Chemetoff did not want to focus on the decorative aspects of the project; instead, he relied on local geography and history in the creation of the transitions from one element to another. The permanent landscape was gradually reorganized: from the horizon of the sea to the city, from the alluvial plains to the hills and vice versa, the artificial and natural elements were stratified, forming parallel lines down to the sea, creating a wide-open landscape. The elements used - containers for seasonal activities, meadows and grass as a continuation of the hill, and white railings along the boulevard - reflected the heritage of the city and fully involved the sea in the renewal of the urban identity of Le Havre. This project was an important initial driving force helping to transform the perception of greenspaces in the city. This is illustrated by the 2020 Equerre d'Argent prize, awarded to landscape designer Michel Desvigne for his work on the renewal of the quai de Southampton in Le Havre, between 2017 and 2019. On the city's southern seafront, the redevelopment of the historic quayside, known as the Grand-Quai, has enabled the greenspaces developed by Alexandre Chemetoff to be fully appreciated by the city, with nearly 10 hectares of public space (Figure 14.4).

Today's important issues, such as biodiversity, landscape, pollution, transport, water resources, and flora and fauna, are no longer restrained within frameworks, or models, with a fixed or limited scale. There is therefore no longer one single way of creating the city, nor one single model. This is especially true in this time of climate change, because movement will be one of the only ways of surviving for both humans and nonhumans. To allow for this, cities must not block these movements.

These different considerations - be they social (the potential for recreational activities) or ecological (the qualities of the ecosystem) - reflect a change in the way we identify and outline natural spaces and the associated ways of protecting them. A shift is taking place, moving away from a strict protection of biodiversity in cities to a broader protection of

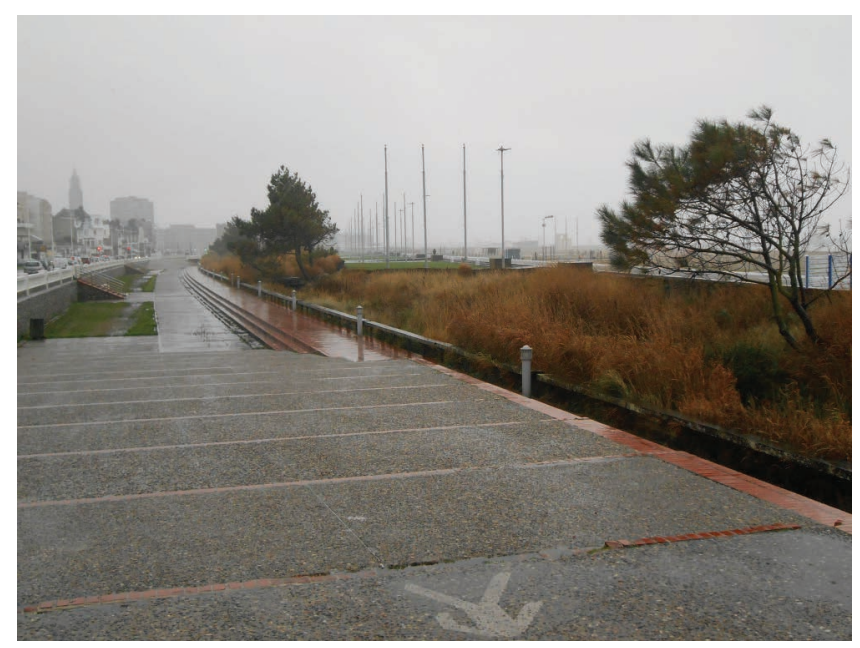

FIGURE 14.4 Aménagement du littoral le Havre. Concepteur Alexandre Chemetoff. Photo (C) Fabienne Fendrich, 2020. 


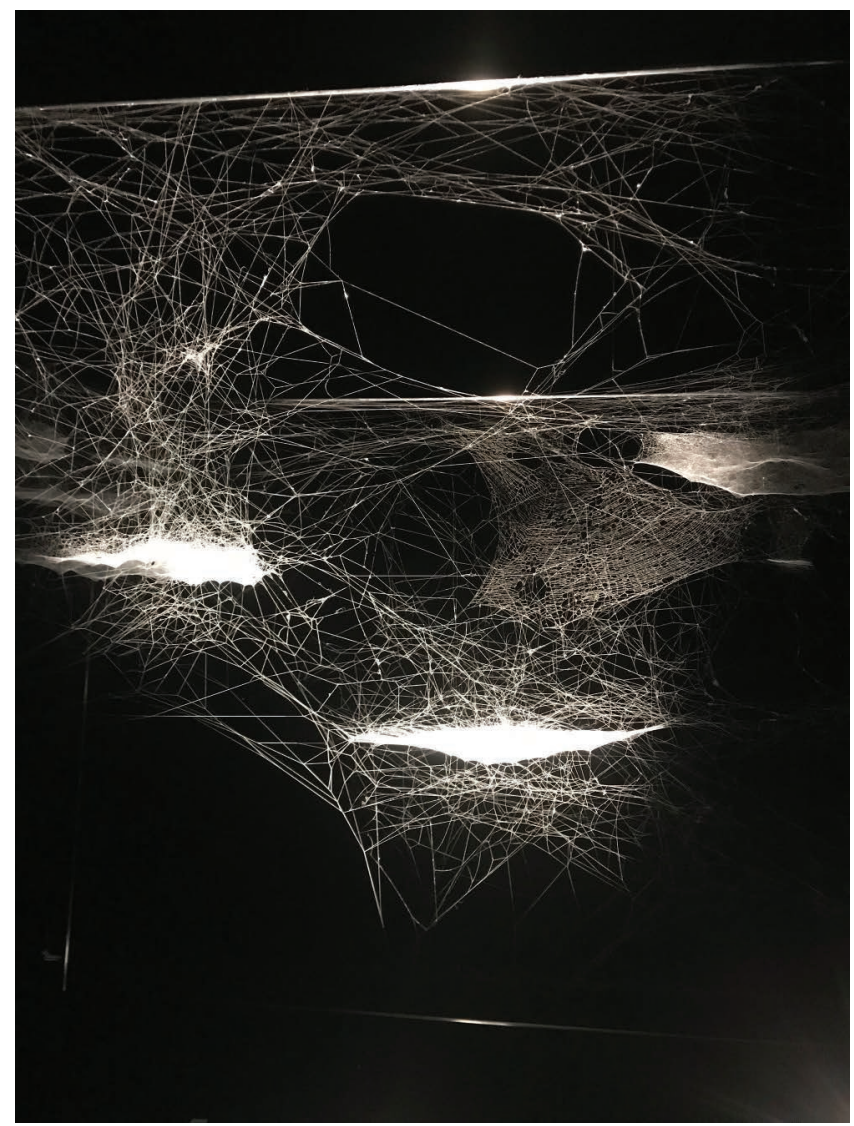

FIGURE 14.5 Exposition “ON AIR.” Tomás Saraceno. Palais de Tokyo. 2018. Photo C Fabienne Fendrich, 2018.

urban nature. Identifying and protecting greenspaces contributes greatly to the attractiveness and development of a city. There are various, more or less direct impacts linked to the presence of numerous protected greenspaces in the city. It is possible to observe and quantify the economic benefits, the impacts on the health and well-being of the inhabitants, the feeling of belonging and being connected to the city, increased knowledge of nature, or the development of more civic behavior. The resulting benefits in terms of the possible different uses (walking, playing sports in a natural setting) or the ecological value (providing continuity with peri-urban greenspaces) are the reasons for this success. An analysis of the new trends that are emerging shows how the function of nature in the city is becoming more complex. With urban development going beyond aesthetics and no longer considered a simple response to a social demand and having become more than a question of regional economic development or a consideration for environmental impact, a need for balance is appearing as an essential factor in urban development plans and strategies. The objective is not to 'stage' nature but rather to co-create a shared project, starting with the city's inhabitants (human and nonhuman) and getting them to participate in a shared design for the future. The exhibition "ON AIR," a 'carte blanche' invitation given to Tomás Saraceno at 
the Palais de Tokyo in 2018, was an artistic symbol, heralding the shift about to occur. Indeed, the exhibition showcased the work of living spiders and presented itself as a fragile and poetic changing ecosystem. There is a multitude of these animate and inanimate presences that coexist, creating works of art and allowing us to perceive new fundamental patterns and topics such as contextuality, frugality, bioclimatic design, or simply everyday life and the desire to inhabit the world (Figure 14.5).

\section{Bibliography}

Berque, A. 2016. La Pensée paysagère. Bastia: Éditions Éoliennes.

Bourgeois-Gironde, S. 2020. Etre la rivière. Paris: Éditions PUF.

Brunon, H. and M. Mosser. 2011. Le Jardin contemporain. Renouveau, expériences et enjeux. Paris: Nouvelles éditions Scala.

Clément, G. 1991. Le Jardin en mouvement. Paris: Éditions Pandora.

Marcel, O. 2008. Paysage visible, paysage invisible. Paris: Éditions Champ Vallon.

Pigeon, P. 2007. L'environnement au défi de l'urbanisation. Rennes: Éditions PUR. 